\title{
A Case of Hypersomnolence with Subclinical Hypothyroidism Treated with Levothyroxine
}

\author{
Minkyeong Kim, Song Hwa Chae, Eun Hye Oh, Baik-Kyun Kim, Dae Jin Kim, Jae Wook Cho \\ Department of Neurology, Pusan National University Yangsan Hospital, Yangsan, Korea
}

\author{
무증상 갑상샘기능저하증과 동반된 과다수면증을 레보티록신으로 치료한 환자 \\ 김민경, 채송화, 오은혜, 김백균, 김대진, 조재욱 \\ 양산부산대학교병원 신경과
}

$\begin{array}{ll}\text { Received } & \text { June 22, } 2015 \\ \text { Revised } & \text { June 24, } 2015 \\ \text { Accepted } & \text { June 26, } 2015\end{array}$

Address for correspondence

Jae Wook Cho, MD

Department of Neurology,

Pusan National University

Yangsan Hospital,

20 Geumo-ro, Mulgeum-eup,

Yangsan 626-770, Korea

Tel: +82-55-360-2122

Fax: $+82-55-360-2152$

E-mail: sleep.cho@gmail.com

\begin{abstract}
We present a patient who complained of excessive daytime sleepiness (EDS), which started three years ago. She had no other medical, neurological, and psychiatric disorders. Nocturnal polysomnography did not indicate any sleep disorders, which might cause daytime EDS, such as obstructive sleep apnea. The following multiple sleep latency test was not compatible for narcolepsy. Her laboratory findings were remarkable for subclinical hypothyroidism, although free T4 and T3 were within reference rage, she had elevated thyroid stimulating hormone. After four weeks of levothyroxine treatment, her EDS resolved. The hypersomnolence, as a presenting symptom of subclinical hypothyroidism, was optimally treated after thyroid hormone replacement.
\end{abstract}

J Sleep Med 2015;12(1):23-25

Key Words: Subclinical hypothyroidism, Levothyroxine, Excessive daytime sleepiness. 과다수면증(hypersomnolence)은 야간 수면에 문제가 없 으면서도 과도한 주간졸림증이 동반되는 수면장애다. International Classification of Sleep Disorder, 3rd edition의 분류에 따르면 type I과 type 2 기면증, 특발성 과다수면증, 클라인-레빈 증후군, 수면부족증후군(insufficient sleep syndrome), 내과적 질환으로 인한 과다수면증, 약물에 의한 과 다수면증, 그리고 정신과적 문제로 인한 과다수면증으로 분 류된다. ${ }^{1}$ 이 중 내과적 질환에 의한 과다수면증으로 진단하 기 위해서는 3 개월 이상 과도한 주간졸림증이 있으며, 다른 정신적 이상이나 수면장애, 약물에 의한 졸림증이 모두 배제 되어야 한다. 그리고 수면잠복기반복검사(multiple sleep latency test, MSLT)에서 평균수면잠복기는 8분 이내로 짧지만 sleep onset rapid eye movement sleep periods(SOREMP)는 2회 이하로 관찰되어야 한다. 주로 파킨슨씨병, 외상성, 유전 성 신경계 질환, 뇌병변장애, 내분비장애, 그리고 대사성 뇌

This is an Open Access article distributed under the terms of the Creative Commons Attribution Non-Commercial License (http://creativecommons.org/licenses/by-nc/3.0) which permits unrestricted non-commercial use, distribution, and reproduction in any medium, provided the original work is properly cited.
병증 등과 동반하여 발생한다.

저자들은 갑상샘기능이 정상이었으나 레보티록신(levothyroxine)에 반응이 좋았던 과다수면증 환자를 경험하여 보고 한다.

\section{증 례}

59세 여자가 3년 전부터 발생한 심한 주간과다졸림증으로 병원에 왔다. 수면 시간은 밤 10 시부터 아침 6시까지 8시간 정도였고 주말과 주간의 차이는 없었다. 밤에 깊은 수면을 취 하는데도 아침에 일어나기가 힘들었으며, 낮잠을 자도 개운 하지 않다고 하였다. Epworth Sleepiness Scale(ESS) 점수는 15 점이었다. 코골이나 수면무호흡, 사지운동증 등 수면을 방 해할만한 다른 증상은 없다고 하였다. 탈력발작이나 수면마 비 등의 증상도 없었다. 과거력에서 3 년 전 건강검진에서 경 미한 갑상샘기능저하증으로 진단받고 약 6개월간 레보티록 신을 복용하였다가 수치가 정상으로 회복되어 중단한 병력이 있었다. 최근 시행한 혈액검사에서도 정상 갑상샘(euthyroid) 


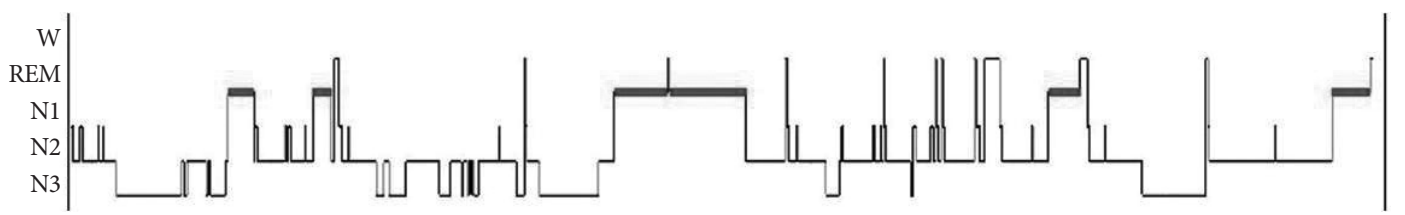

Figure 1. The hypnogram of night polysomnography. W: wake, REM: rapid eye movement sleep, N1: stage I sleep, N2: stage II sleep, N3: stage III sleep.

Table 1. The multiple sleep latency test results

\begin{tabular}{cccc}
\hline Trial & Sleep latency $(\mathrm{min})$ & Sleep stage & SOREMP \\
\hline 1st & 4 & $\mathrm{~N} 1, \mathrm{~N} 2$ & - \\
2nd & 5 & $\mathrm{~N} 1, \mathrm{~N} 2$ & - \\
3rd & 1 & $\mathrm{~N} 1, \mathrm{~N} 2$ & - \\
4th & 1 & $\mathrm{~N} 1, \mathrm{~N} 2, \mathrm{~N} 3$ & - \\
5th & 2 & $\mathrm{~N} 1, \mathrm{~N} 2, \mathrm{~N} 3$ & - \\
\hline
\end{tabular}

SOREMP: sleep onset rapid eye movement sleep period, N1: stage I sleep, N2: stage II sleep, N3: stage III sleep

상태로 판단되어 약물 복용은 하지 않았다. 야간 수면다원검 사를 시행하였는데 510.5 분의 검사시간 동안 489.5 분 수면을 취하여 수면효율은 96\%였고, Wakefulness After Sleep Onset 은 5\%였다. 수면잠복기는 0.8 분으로 짧았으나 렘수면 잠복기 (REM latency)는 79.5분으로 정상이었다. 수면 1단계는 5.8\%, 수면 2단계는 $44.4 \%$, 수면 3단계는 $22.6 \%$ 였으며, 렘수면은 27.2\%였다(Fig. 1). 무호흡저호흡지수(Apnea Hypopnea In$\mathrm{dex})$ 는 $1.7 / \mathrm{hr}$ 로 정상이었고 사지운동증은 없었다. 수면다원 검사에 이어 시행한 5 회의 수면잠복기반복검사에서 평균 수 면잠복기는 2.6분으로 짧아져 있었으며 SOREMP는 관찰되 지 않았다(Table 1). 혈액검사에서 자동혈구분석, 신장기능 및 간기능검사 수치, 전해질, 혈당 등은 정상범위였고 갑상샘 기능검사에서 $\mathrm{T} 3$ 와 free $\mathrm{T} 4$ 는 각각 $1.01 \mathrm{ng} / \mathrm{mL}$ (참고치 0.58 1.59 ), $1.12 \mathrm{ng} / \mathrm{dL}$ (참고치 0.7 1.48)로 정상이었으나 갑상샘 자극호르몬(thyroid stimulating hormone, TSH)이 $9.98 \mu \mathrm{IU} /$ $\mathrm{mL}$ (참고치 0.27 4.2)로 높았다. 항갑상선항체 검사는 시행 하지 않았다. 수면검사와 병력을 종합하여 기면증, 수면부족 증후군 등을 배제한 과다수면증으로 생각하였고 갑상샘기 능이 이와 연관되었을 가능성을 고려하여, 내분비내과와 상 의하여 레보티록신을 하루 $0.05 \mathrm{mg}$ 복용하면서 경과를 보기 로 하였다. 4 주 후 환자는 주간과다졸림증이 많이 호전되었다 고 하였으며 ESS 점수도 7점으로 감소하였다. 갑상샘 기능 재평가는 환자의 거부로 시행하지 못하였다.

\section{고 찰}

본 환자는 3년 동안 지속된 주간과다졸림증을 호소하였 다. 야간 수면다원검사에서 상당히 짧은 수면잠복기를 보여
과도하게 졸린 상태임을 알 수 있었으나, 수면효율이 높았고 수면무호흡이나 사지운동증 등 수면을 방해하는 별다른 문 제를 찾을 수 없었다. 또한, 병력과 수면다원검사에서 전체 수면시간은 8시간 내외로 특발성 수면과다증처럼 증가하지 는 않았다. MSLT에서도 평균 수면잠복기는 짧았으나 SOREMP는 없었다.

환자의 주간졸림증 발생 시점이 갑상샘기능저하증으로 처 음 진단받은 시기와 비슷하여 수면검사와 더불어 갑상샘기 능평가를 시행하였다. 혈중 $\mathrm{T} 3$, free $\mathrm{T} 4$ 는 정상이었고 갑상샘 의 기능 변화를 시사하는 서맥, 빈맥, 변비, 점액부종(myxedema) 등의 임상증상은 없었으나 TSH가 상승한 것으로 미 루어, 무증상 갑상샘기능저하증(subclinical hypothyroidism) 상태라고 생각할 수 있었다. 무증상 갑상샘기능저하증 혹은 무증상 갑상샘기능항진증 환자의 수면에 대해서는 잘 알려 져 있지 않지만, 최근 연구에 의하면 주관적으로나 객관적 검 사에서 질적으로 의미 있는 수면의 변화는 없었다. ${ }^{2}$ 그러나 무증상 갑상샘기능저하증 환자의 $13 \%$ 에서 $\mathrm{ESS}$ 점수 10 점 이상의 주간졸림증을 호소한다고 하며, 갑상샘기능저하증과 연관된 특발성 과다수면증에서 레보티록신이 효과가 좋았 던 연구결과가 있어 본 증례에서도 레보티록신을 사용해 보 기로 하였다.,3 기면증이나 특발성 과다수면증 등과 동반된 주간졸림증에 대해서는 일반적으로는 모다피닐이나 메틸페 니데이트와 같은 중추신경자극성 각성제를 사용하지만, 그 외 내과적 질환이나 약물에 의한 졸림증의 치료에서는 아직 각성제 사용에 대한 근거가 없으며 원인을 제거하는 것을 먼 저 고려한다. ${ }^{4}$

각성과 연관된 신경전달물질은 히스타민, 노르에피네프린, 도파민, 세로토닌, 하이포크레틴, 그리고 아세틸콜린 등이며, 이와 연관된 중요한 중추는 히스타민성 조면유두체핵(tuberomammillary nucleus), 뇌교의 노르아드레날린성 청색반점 (locus ceruleus), 뇌간의 그물활성계(reticular activating system), 그리고 시상하부 등이다. 갑상샘호르몬이 직접적으로 각성을 담당한다는 증거는 부족하지만, 외부환경이나 신체 내부의 이상변화를 감지하는 데 중요한 역할을 하는 특성상 각성에도 중요한 기능을 담당할 것이라 추측할 수 있다. Pereira 등의 연구에 따르면 갑상샘호르몬은 특히 히스타민, 노 르아드레날린과 긴밀하게 작용한다고 알려져 있어, 아마도 
이러한 신경전달물질과의 상호작용을 통해 각성효과를 나타 낼 것으로 생각된다. ${ }^{5,6}$

실제로 레보티록신의 투여가 시상하부, 시상, 대뇌피질의 히스타민 농도를 올린다는 연구가 있었으며, 78 갑상샘기능 이 저하된 쥐의 시각교차앞구역(preoptic area)에 갑상샘호 르몬을 주입하였을 때 렘수면과 비렘수면, 나아가 전체수면 시간이 짧아지고 각성이 증가하는 양상이 관찰되었다는 보고 도 있다. ${ }^{8}$ 또한, Strawn 등은 정상인에서 도파민 대사물인 호 모바닐린산(homovanillic acid)의 뇌척수액 내 농도가 혈청 $\mathrm{TSH}$ 농도와 반비례한다는 연구결과를 발표하였다. ${ }^{9}$

갑상샘호르몬은 $\mathrm{TSH}$ 뿐만 아니라 교감신경과 부교감신경 등 자율신경에도 지배를 받으며, 음성되먹임에 의해 조절된 다. ${ }^{10}$ Shinno 등은 갑상샘기능이나 TSH의 농도가 변하면 hypothalamo-pituitary-thyroid 축에 변화가 오면서 히스타민 과 도파민 등의 신경전달물질에도 영향을 미칠 수 있고, 이러 한 변화가 특발성 과다졸림증 원인의 하나가 될 수 있을 것 이라고 주장하였다. ${ }^{3}$

본 증례에서 환자는 임상적으로 특별히 갑상샘기능저하증 의 증상이 없었고 $\mathrm{T} 3$ 와 free $\mathrm{T} 4$ 가 정상범위인 무증상 갑상 샘기능저하증이었지만, 레보티록신은 과다졸림증을 줄이는 데 효과가 있었다. 과거에도 무증상 갑상선기능저하증 환자 에게 레보티록신의 투여가 효과가 있었던 연구가 있었으나 대부분 660분이 넘는 긴 야간 수면시간을 동반한 특발성 수 면과다증 증례들이었던 반면 본 증례는 야간 수면시간은 정 상이었다. 따라서 긴 야간 수면 동반 여부에 상관없이 레보 티록신에 반응하는 환자들이 존재할 것으로 생각할 수 있다.
과다졸림증 환자에서 수면다원검사에 특이 소견이 없고 MSLT에서 기면증에 부합하지 않을 경우에는 갑상샘에 대한 과거 병력 청취와 갑상샘기능검사를 시행하여 필요 시 레보 티록신을 투여하는 것이 도움이 될 것이라 사료된다.

\section{REFERENCES}

1. American Academy of Sleep Medicine. International classification of sleep disorders, 3rd edition: diagnostic and coding manual. Westchester, IL: American Academy of Sleep medicine, 2014.

2. Akatsu H, Ewing SK, Stefanick ML, et al. Association Between Thyroid Function and Objective and Subjective Sleep Quality in Older Men: The Osteoporotic Fractures in Men (MrOS) Study. Endocr Pract 2014; 20:576-586.

3. Shinno H, Ishikawa I, Yamanaka M, et al. Effect of levothyroxine on prolonged nocturnal sleep time and excessive daytime somnolence in patients with idiopathic hypersomnia. Sleep Med 2011;12:578-583.

4. Mayer G, Benes H, Young P, Bitterlich M, Rodenbeck A. Modafinil in the treatment of idiopathic hypersomnia without long sleep time--a randomized, double-blind, placebo-controlled study. J Sleep Res 2015; 24:74-81.

5. Pereira JC Jr, Andersen ML. The role of thyroid hormone in sleep deprivation. Med Hypotheses 2014;82:350-355.

6. Dratman MB, Gordon JT. Thyroid hormones as neurotransmitters. Thyroid 1996;6:639-647.

7. Upadhyaya L, Agrawal JK. Effect of L-thyroxine and carbimazole on brain biogenic amines and amino acids in rats. Endocr Res 1993;19:87-99.

8. Moffett SX, Giannopoulos PF, James TD, Martin JV. Effects of acute microinjections of thyroid hormone to the preoptic region of hypothyroid adult male rats on sleep, motor activity and body temperature. Brain Res 2013;1516:55-65.

9. Strawn JR, Ekhator NN, D’Souza BB, Geracioti TD Jr. Pituitary-thyroid state correlates with central dopaminergic and serotonergic activity in healthy humans. Neuropsychobiology 2004;49:84-87.

10. Cardinali DP, Vacas MI, Gejman PV, et al. The sympathetic superior cervical ganglia as "little neuroendocrine brains". Acta Physiol Lat Am 1983;33:205-221. 